\title{
Utilização de Cloridrato de Polihexametileno Biguanida (PHMB) na desinfecção de indústrias cervejeiras
}

\author{
Petherson D. Santos ${ }^{1}$, Paulo H. S. Fernandes ${ }^{2}$ \\ ${ }^{1}$ Universidade Severino Sombra, CECETEN, Discente do curso de Bacharel \\ em Química Industrial, petherson.santosdig.com.br \\ ${ }^{2}$ Universidade Severino Sombra, CECETEN, Docente do curso de Bacharel em \\ Química Industrial, ph_fernandes@globo.com
}

Resumo. Este artigo visa comprovar a eficiência da ação bactericida do Cloridrato de Polihexametileno Biguanida (PHMB), na desinfecção de indústrias cervejeiras bem como verificar seu custo benefício. Para tal, utilizou-se o produto Biguatin 400 (que contém 4\% do princípio ativo) em diferentes concentrações nos tanques de fermentação de uma planta piloto de cervejaria, seguido de análise microbiológica. Ao final disto, avaliaram-se os resultados que mostraram o grau de eficiência do princípio ativo.

\section{Introdução}

"A higienização é uma das maiores preocupações dos cervejeiros. O seu objetivo é eliminar ou, pelo menos, reduzir a níveis aceitáveis a quantidade de bactérias e outros contaminantes presentes no equipamento e utensílios utilizados no processo de produção de cerveja." [COSTA, E . 2008]

A utilização de antimicrobianos nas formulações de sanitizantes e desinfetantes é essencial para a manutenção de altos níveis de padrões de higiene. Estes antimicrobianos são particularmente importantes em ambientes de alto risco de contaminação, tais como indústrias de processamento de alimentos e hospitais.

Nos últimos anos a necessidade de um antimicrobiano efetivo para ser utilizado nestes ambientes tem sido altamente importante e extensivamente estudada. Seguindo esta linha, o grupo das biguanidas vem sendo estudado como um potencial e versátil antimicrobiano desde 1879. [FRANZIN, M. 2005]

Como exemplos primários destas biguanidas temos Clorexidina que é uma biguanida monomérica e a bis(biguanida) ou biguanida polimérica.

\subsection{Problema}

Microrganismos contaminantes podem competir com as leveduras pelos nutrientes, neste caso os açúcares presentes no mosto, limitando assim a atividade fermentativa das mesmas.

Da atividade destes microrganismos indesejáveis resultam também alguns produtos secundários que irão conferir à cerveja gostos e aromas indesejáveis, sendo as bactérias láticas o grupo mais comum. Estas são responsáveis pelo desenvolvimento de gosto e aroma estranhos ao produto, devido à intensa produção de ácido lático.

Os sanitizantes utilizados atualmente, não possuem atuação muito eficiente sobre certos tipos de microorganismos, o que compromete a qualidade de muitas cervejas. 
Seria a utilização do PHMB a solução mais eficiente contra as bactérias láticas e demais contaminantes?

\subsection{Hipótese}

O espectro de atuação do PHMB sobre microorganismos é muito maior e mais eficiente do que qualquer outro sanitizante, tendo um custo/benefício maior. Sendo assim acredita-se numa eficiência máxima de atuação do PHMB sobre as bactérias láticas e demais contaminantes [FRANZIN, M. 2005].

\section{Objetivos}

\subsection{Objetivo Geral}

A presente pesquisa visa comparar a eficiência do processo de sanitização de todos os equipamentos envolvidos na fabricação/transporte de mosto/cerveja, mediante utilização de um princípio ativo específico (PHMB).

\subsection{Objetivo específico}

Promover através de experimentos práticos, a otimização do processo de sanitização em indústrias cervejeiras e seus respectivos custo/benefícios.

\section{Revisão da Literatura}

"De nada vale utilizar os melhores ingredientes, o melhor equipamento, a melhor receita se descuidamos de uma etapa tão importante como é a higienização!" [COSTA, E., 2008].

Para COSTA (2008) deve-se ter a preocupação em reduzir a contaminação das cervejarias a níveis aceitáveis. Para tanto, procedeu-se uma limpeza com água e detergente com auxílio de esponja. Para a desinfecção foram utilizados produtos à base de ácidos, bases, cloro, iodo, etc. Além disso, utilizou-se hidróxido de sódio que garantiu uma eficiente desinfecção.

Para FRANZIN (2005) também deve-se ter a preocupação em reduzir a níveis aceitáveis (tendendo a zero), a contaminação microbiana de equipamentos, tubulações e utensílios que são utilizados em indústrias alimentícias, que possam vir a alterar o produto em qualquer uma de suas características sensoriais. Para tal, utilizou-se o PHMB (Cloridrato de Polihexametileno Biguanida) em comparação com outros desinfetantes, onde este mostrou maior eficiência do PHMB sobre os demais.

KUNZE, W., apresenta variações quanto a concentração e tempo de circulação de detergentes e desinfetantes, de acordo com o tipo de cerveja a ser fabricada e material dos equipamentos e utensílios utilizados no processo.

Os produtos de desinfecção buscam, basicamente, a eliminação dos microorganismos que podem contaminar uma planta de cervejaria. "O conhecimento sobre o tipo de problema que se deseja eliminar é fundamental para o sucesso do procedimento. [TSCHOPE, E.C., 2001]". A flora contaminante numa cervejaria é, principalmente, composta por bactérias láticas e leveduras selvagens.

Os principais produtos de desinfecção utilizados são produtos à base de: 
- Cloro;

- Ácido peracético;

- Quaternário de amônia (banhos de imersão);

Hoje os produtos mais utilizados em processos CIP (clean-in-place) numa cervejaria são aqueles à base de ácido peracético em virtude de:

- Amplo espectro de atuação;

- Formação de produtos residuais compatíveis com a cerveja (ácido acético e oxigênio);

- Não necessidade do enxágüe final.

As principais classes de microorganismos alteradores da cerveja são: bactérias ácido láticas, bactérias acéticas, anaeróbias gram negativas, enterobacteriaceae, leveduras selvagens, Zymomonas mobilis.

\subsection{Bactérias}

São agentes deteriorantes comuns em cerveja. São comumente divididas nas categorias gram positivas e gram negativas. As bactérias gram positivas, que trazem os maiores problemas para a cerveja, são as bactérias láticas pertencentes aos gêneros Lactobacillus e Pediococcus, sendo que pelo menos 10 espécies de lactobacilos podem causar danos a esse produto. Os lactobacilos cervejeiros são heterofermentativos e homofermentativos e produzem ácido lático e acético, dióxido de carbono, etanol e glicerol como produtos finais, com algumas espécies também produzindo diacetil. Os Pediococos são homofermentativos e possuem 6 espécies identificadas, mas a espécie predominante econtrada na cerveja é Pediococcus damnosus, sendo sua infecção caracterizada pela formação de diacetil. Entre as bactérias gram negativas que causam danos à cerveja incluem-se as Bactérias acéticas (Acetobacter, Gluconobacter), e certos membros da família das enterobactérias (Escherichia, Aerobacter, Klebsiella, Citrobacter, Obesumbacterium), como também Zymomonas, Pectinatus e Megasphaera [VENTURINI Filho, W. G., 2005].

\subsection{Leveduras selvagens}

Afetam a velocidade de fermentação, atenuação final, floculação e paladar do produto final.

\subsection{A espécie não cervejeira}

Pode ocorrer produção de produtos off flavor, semelhantes aos produzidos pelas bactérias.

\subsection{PHMB - Mecanismo de Ação}

De acordo com FRANZIN (2005), para entendimento do mecanismo de ação do PHMB é importante conhecer a estrutura celular de bactérias Gram-negativas, associando os vários componentes bioquímicos que as compõem.

A membrana externa ocorre somente nas espécies Gram-negativas, tais como, Escherichia coli e Pseudomonas aeruginosa servindo como uma proteção extra da membrana citoplasmática contra o ataque de toxinas, tornando mais difícil a ação de 
antimicrobianos dificultando a sua penetração na célula bacteriana. Abaixo desta "capa" e ligada a ela, está a parede celular responsável por garantir a integridade da estrutura celular evitando que a alta pressão osmótica interna provoque danos a célula.

Seguindo mais para o interior da célula, temos a membrana citoplasmática ligada a parede celular e totalmente em contato com o citoplasma. A membrana citoplasmática possui diferentes propriedades, tais como, permeabilidade seletiva que garante a presença de diversos tipos de proteínas, as quais estão embebidas em fosfolipídeos que formam a membrana. Além disso a membrama citoplasmática é responsável em manter as concentrações citoplasmáticas dos íons que são transportados eletronicamente para dentro da célula devido as alterações de $\mathrm{pH}$ e potencial dos variados tipos "capas" ou "membranas" (fig. 3).

O mecanismo de ação do PHMB vem sendo estudado por vários cientistas ao longo de décadas. Baseado no trabalho destes cientistas, a seqüência bactericida proposta pela Imperial Chemical Industries [ICI, 1986] começa com uma rápida atração do PHMB catiônico na superfície bacteriana negativamente carregada provocando uma falha no mecanismo de defesa da célula e a ruptura da parede da célula. O PHMB então é atraído para a membrana citoplasmática, onde causa a perda de substâncias de baixo peso molecular, tais como íons de Potássio, Cálcio e a inibição de enzimas responsáveis pela união da membrana, tais como o ATPase. A grande ruptura subsequente da membrana citoplasmática pode então levar à perda de substâncias macromoleculares (ex. Nucleotídeos) e à preciptação das substâncias celulares.

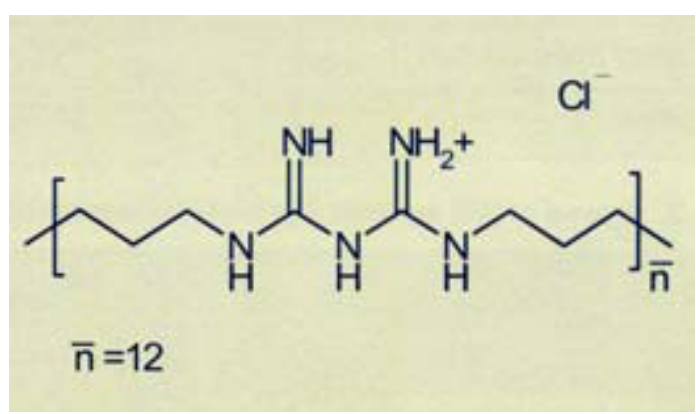

Figura 1: PHMB - Cloridrato de Polihexametileno Biguanida

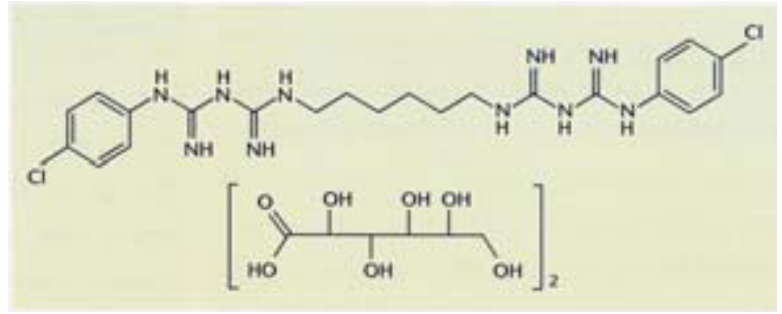

Figura 2: Clorexidina 
(Polyhexanide is represented by MMY)

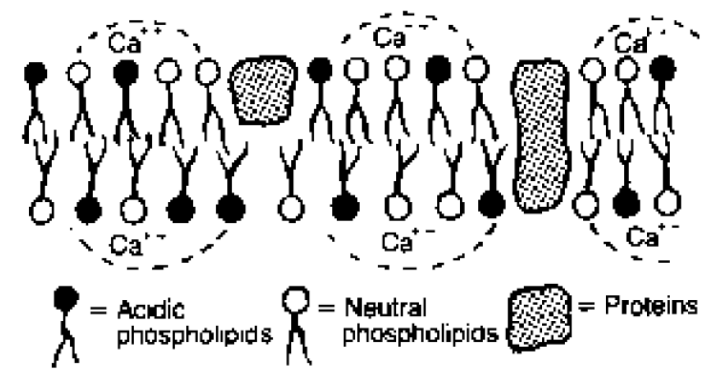

Figura 3: Mecanismo de ação do polihexametileno biguanida (PHMB).

a) membrana citoplasmática bacteriana conforme modelo do "Mosaico fluido" estabilizado por íons de Ca e mistura de fosfolipídeos (Figura 4).

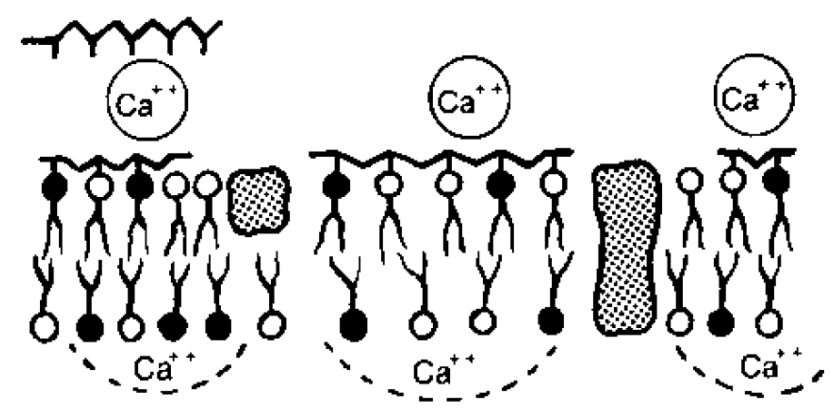

Figura 4

b) o PHMB sobre a superfície de cátions, ligada aos fosfolipídeos, causa mudança na estrutura (figura5).

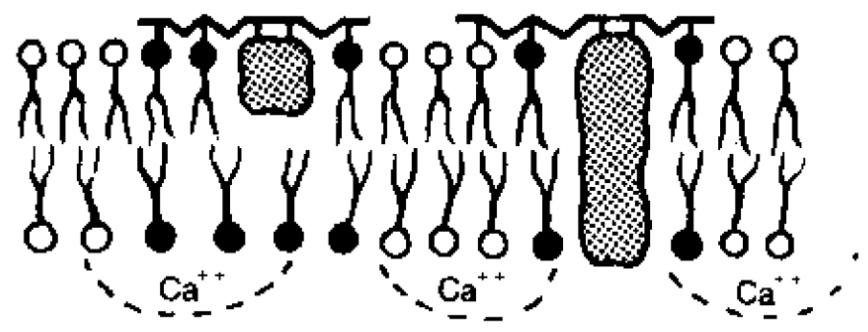

Figura 5

c) o PHMB induz a separação da camada de fosfolipídeos, efeitos concentrados na área da proteína integral ; causa aumento da permeabilidade da membrana, fluxo de $\mathrm{K}+\mathrm{e}$ perda da função da membrana (Figura 6) 


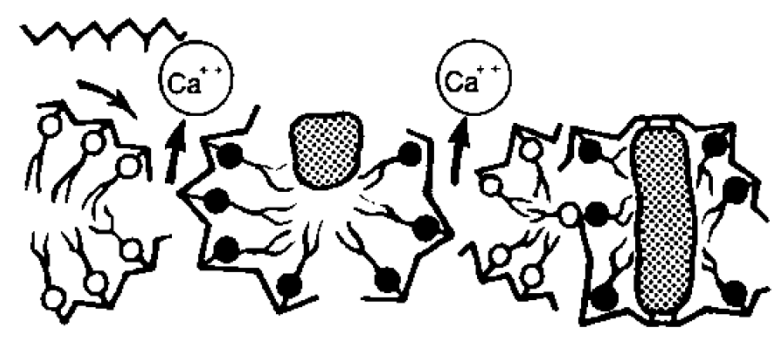

Figura 6

d) Ruptura extensiva da membrana citoplasmática com vazamento dos componentes macromoleculares e precipitação do conteúdo celular

\subsection{Aplicações}

O PHMB vem sendo estudado a décadas [ROSENTHAL et al, 1982] como ingrediente ativo em formulações de desinfetantes para indústrias alimentícias, possuindo uma excelente atividade no controle de microrganismos patogênicos, tais como, Escherichia coli, Staphylococcus aureus e Pseudomonas aeruginosas bem como endoesporos de bactérias termoresistentes (Bacillus sp.). "Seu amplo espectro de ação na presença de matéria orgânica (leite, sangue, albumina, etc) aliado a baixa toxicidade em mamíferos, baixa corrosividade e formação de espuma garantem ao PHMB um melhor custo benefício quando comparado aos tradicionais desinfetantes à base de quaternário de amônio." [FRANZIN, M. 2005]

Desinfetantes contendo PHMB podem ser utilizados na desinfecção de equipamentos, pisos, paredes em sistemas abertos ou CIP (clean-in-place) através de aplicação manual, imersão ou recirculação seguida de enxáguie com água potável conforme "Resolução 211/MS/ANVS, de 18 de Junho de 1999 publicada no D. O. U em 26 de Junho de 1999".

A boa performance do PHMB como ingrediente ativo em desinfetantes para indústrias alimentícias quando comparado com outros ativos, pode ser evidenciado através dos resultados obtidos em testes realizados com base em protocolos aceitos pela Comunidade Européia sobre condições de uso especifico. [FRANZIN, M. 2005]

\subsubsection{PHMB - Formulando Desinfetantes}

Como o PHMB possui um caráter catiônico, as formulações de desinfetantes devem seguir as mesmas orientações utilizadas quando do uso de quaternários de amônio.

No entanto dependo da aplicação final, uma grande variedade de surfactantes não iônicos, co-solventes, espessantes e agentes sequestrantes, poderão ser utilizados garantindo um sinergismo da formulação contendo baixas concentrações de PHMB e conseqüentemente obtendo-se um melhor custo benefício. [FRANZIN, M. 2005]

De acordo com FRANZIN (2005), a alta solubilidade do PHMB em água permite formulações límpidas e transparentes mesmo em condições extremamente alcalinas ou ácidas desde que observadas algumas orientações básicas. Desinfetantes ácidos e alcalinos ( $\mathrm{pH}$ entre 4 a 13) transparentes podem ser obtidos com a utilização de diversos tipos de ácidos e bases desde que respeitando alguns procedimentos de adição. 
Em situações onde a aparência da superfície após a desinfecção é um fator determinante e importante (catering, restaurantes, banheiros, cozinhas, etc) as formulações contendo PHMB são reconhecidas como sendo as ideais, uma vez que após a sua secagem não deixam manchas na superfície não alterando o brilho das mesmas. Tal característica não ocorre com os compostos de quaternário de amônio devido à presença de cadeias de ácidos graxos.

\section{Metodologia}

Obedecendo um cronograma para execução dos ensaios, primeiramente procedeu-se o pré-enxágue seguido de higienização convencional em tanques de fermentação com soda cáustica a $3 \%$ por 20 minutos. Logo após, coletou-se uma amostra da água de enxágue para análise microbiológica inicial de bactérias láticas (Agar MRS), bactérias heterotróficas (Agar Standard) e Bolores e Leveduras (Agar mosto) em triplicata, por filtração por membrana, utilizando-se de métodos oficiais de análises microbiológicas, de acordo com a Instrução Normativa 62 do Ministério da Agricultura Pecuária e Abastecimento.

Após a higienização, efetuou-se a desinfecção dos tanques de fermentação com o Biguatin 400 (4\% de PHMB) nas concentrações de 0,2\% e 1,1\% (2 tanques para cada concentração) por 10 minutos, com posterior coleta de amostra de água do último enxágüe, seguindo para as mesmas análises microbiológicas em triplicata.

Ao final das análises, obtiveram-se os resultados e procedeu-se o estudo dos mesmos (tabela 1).

\section{$5 \quad$ Resultados e discussões}

Tabela 1. Resultados obtidos nas análises microbiológicas com Biguatin $\mathbf{4 0 0}$ na concentração de $0,2 \%$

\begin{tabular}{|l|c|r|r|r|r|r|}
\cline { 2 - 7 } \multicolumn{1}{c|}{} & \multicolumn{7}{c|}{ Tanque 1 } \\
\hline \multicolumn{1}{c|}{ Análise } & Pré-desinfecção *UFC/100ml & \multicolumn{1}{c|}{ Pós-desinfecção *UFC/100ml } \\
\hline Bolores e leveduras & 2 & 2 & 1 & 1 & 1 & 1 \\
\hline Bact. Lácticas & $* *$ Aus & Aus & Aus & Aus & Aus & Aus \\
\hline Bact. Heterotróficas & 13 & 9 & 14 & Aus & Aus & Aus \\
\hline \multicolumn{8}{|c|}{ Tanque 2 } \\
\hline \multicolumn{8}{|c|}{ Análise } & Pré-desinfecção *UFC/100ml & Pós-desinfecção *UFC/100ml \\
\hline \multicolumn{1}{|c|}{ Bolores e leveduras } & Aus & Aus & 1 & Aus & Aus & 1 \\
\hline Bact. Lácticas & Aus & Aus & Aus & Aus & Aus & Aus \\
\hline Bact. Heterotróficas & 65 & 56 & 50 & Aus & Aus & Aus \\
\hline
\end{tabular}


Tabela 2. Resultados obtidos nas análises microbiológicas com Biguatin $\mathbf{4 0 0}$ na concentração de $1,1 \%$

\begin{tabular}{|c|c|c|c|c|c|c|}
\hline & \multicolumn{6}{|c|}{ Tanque 3} \\
\hline Análise & \multicolumn{3}{|c|}{ Pré-desinfecção *UFC/100ml } & \multicolumn{3}{|c|}{ Pós-desinfecção *UFC/100ml } \\
\hline Bolores e leveduras & 2 & Aus & Aus & Aus & Aus & Aus \\
\hline Bact. Lácticas & Aus & Aus & Aus & Aus & Aus & Aus \\
\hline Bact. Heterotróficas & 10 & 09 & 13 & Aus & Aus & Aus \\
\hline & \multicolumn{6}{|c|}{ Tanque 4} \\
\hline Análise & \multicolumn{3}{|c|}{ Pré-desinfecção *UFC/100ml } & \multicolumn{3}{|c|}{ Pós-desinfecção *UFC/100ml } \\
\hline Bolores e leveduras & 4 & 2 & 3 & Aus & Aus & Aus \\
\hline Bact. Lácticas & Aus & Aus & Aus & Aus & Aus & Aus \\
\hline Bact. Heterotróficas & 22 & 31 & 27 & Aus & Aus & Aus \\
\hline
\end{tabular}

\section{*UFC: Unidade Formadora de Colônia}

\section{**AUS: Ausência}

Nos experimentos realizados, as análises microbiológicas comprovam que o princípio ativo já tem uma certa atuação na redução ou eliminação de carga microbiana, na concentração mínima estipulada pelo fabricante $(0,2 \%)$ e eliminação total de toda carga microbiana na concentração média de $1,1 \%$. A não ocorrência de detecção de bactérias lácticas, deve-se ao fato de que a higienização dos tanques vem sendo muito eficiente e provavelmente pelo fato da planta de bebidas não ser usada continuamente.

Baseados em preço médio do produto para o estado do RJ, o custo para desinfecção nas concentrações de 0,2 e 1,1\% ficaria, respectivamente, em torno de $\mathrm{R} \$ 0,04$ e $\mathrm{R} \$ 0,23$ / litro de solução de Biguatin que contém $4 \%$ de princípio ativo. Ou seja, por exemplo, em uma solução de 700 litros numa concentração de $0,2 \%$, houve atuação de $56 \mathrm{ml}$ do princípio ativo PHMB.

\section{Conclusão}

Com base nos resultados obtidos, conclui-se que aliando o amplo espectro de atuação do princípio ativo PHMB, que se mostra maior que os princípios ativos convencionais, ao seu custo relativamente baixo, tem-se uma desinfecção eficiente em sistemas CIP de indústrias cervejeiras. Com isso, é possível garantir a qualidade e a segurança necessárias na produção de bebidas.

\section{Agradecimentos}

Agradeço primeiramente a Deus por ter me capacitado até aqui, ao meu orientador Paulo Henrique Simões Fernandes pelo encaminhamento no transcorrer do trabalho, ao CTS (Centro de Tecnologia SENAI-RJ Alimentos e Bebidas) nas pessoas de Imar Oliveiro de Araújo, meus co-orientadores Mestre José Gonçalves Antunes e Mestre cervejeiro Eng. Cláudio José Gonçalves de Matos pela disponibilização de tempo, atenção e grande conhecimento que muito me ajudaram na realização deste trabalho. À Silvia Agibert, e à Coordenadora de bebidas Elisa Helena pela disponibilização do 
laboratório de microbiologia do CTS e à Luana Tashima pelo auxílio na execução das análises.

Registro também meu grande agradecimento à empresa Newdrop - Sistemas de Higienização, na pessoa de Sergio Batista Moresco, por gentilmente nos ceder o produto Biguatin 400 sem o qual este trabalho não poderia ser realizado com êxito.

\section{Referências Bibliográficas}

COSTA, E., A importância da higienização; disponível em $<$ http://brewingsessions.blogspot.com/2008/07/importância-da-higienizao.html>; acesso em 14/02/2009.

FRANZIN, M., Biguanida Polimérica Versatilidade e Diversificação em um só Produto; disponível em $<$ http://www.opportuna.com.br/produtos/arquivos/Biguanida_Arch_2008612115838. pdf>; acesso em 09/02/2009.

Instrução Normativa 62 do Ministério da Agricultura Pecuária e Abastecimento Anexo VII.

TSCHOPE, E. C., Microcervejarias e cervejarias: a História, a Arte e a Tecnologia. Ed. Aden, SP, 2001, $1^{\text {a }}$ edição.

VENTURINI Filho, W.G., Tecnologia de Bebidas, Ed. Edgard Blücher Ltda., SP, $1^{\text {a }}$ edição, 2005, pág. 358-359.

KUNZE, W. Technology Brewing and Malting. Berlim: VLB, 2003.

ROSENTHAL I, Juven B J and Ben-Hur E 1982. Evaluation of poly(hexamethylene biguanide $\mathrm{HCl}$ ) as a biocide in the food industry. J. Food Safety 4, 191-197.

ICI Specialty Chemicals Technical Literature Ref. 30-15: Products for the formulation of solid surface disinfectants and detergent sanitizers. 